
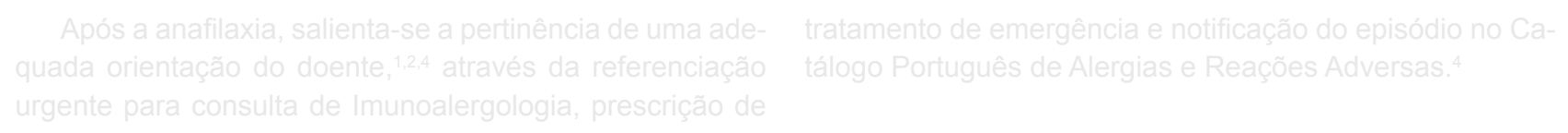

\section{Carta ao Editor: Ainda a Propósito do Delirium}

\section{Letter to the Editor: Still About Delirium}

Palavras-chave: Confusão; Sinais Vitais Keywords: Confusion; Delirium/diagnosis; Delirium/drug therapy; Vital Signs

Lemos com muito interesse e especial agrado uma revisão recentemente publicada na vossa revista dedicada ao delirium. ${ }^{1}$ Com muito interesse por ser um tema importantíssimo, transversal a toda as especialidades em Medicina; e com especial agrado porque nós Psiquiatras sentimos que de facto tem havido graves insuficiências no conhecimento teórico e na abordagem prática desta síndrome neuropsiquiátrica. Não são poucas as vezes que a reconhecemos em doentes que nos chegam pela urgência hospitalar, sem que tenha havido uma triagem correta, por parte de outras especialidades. Muitos desses doentes acabam internados em enfermarias de Psiquiatria e vêm o seu prognóstico agravado por um atraso no diagnóstico e tratamento corretos, por vezes com desfecho trágico. Só por isso gostaríamos de felicitar os autores e os editores por terem publicado este artigo. Ainda assim, e no entanto, há aspetos que merecem, no nosso entender, alguns esclarecimentos:

1) Os autores alcunharam o delirium de $7^{\circ}$ sinal vital, mas ficámos com uma dúvida: quais são os outros seis? É que numa breve pesquisa na PubMed encontrámos, pelo menos nove (e não seis) sinais vitais. Os seis clássicos: pressão arterial, pulso, temperatura, respiração, peso e

\section{REFERÊNCIAS}

1. Prayce R, Quaresma F, Neto IG. Delirium: o $7^{\circ}$ parâmetro vital? Acta Med Port. 2018;31:51-8.

2. McCarthy FM. Vital signs--the six-minute warnings. J Am Dent Assoc. altura²; e ainda três contemporâneos: status funcional, ${ }^{3}$ dor ${ }^{4}$ e sofrimento. ${ }^{5}$ Haverá consenso nesta matéria?

2) Os autores não fizeram referência a sinónimos de delirium. É importante recordar os leitores que delirium é equivalente a outras expressões tantas vezes usadas em contexto clínico, dos quais gostaríamos de destacar apenas estado confusional agudo. Mas há outros sinónimos, ${ }^{6}$ que vão sendo usados consoante a especialidade (e.g. encefalopatia hepática na Gastrenterologia, etc...).

3) O artigo também não alerta para um lapso que por vezes encontrarmos nalgumas traduções infelizes. Estamos a referir-nos à confusão entre delirium e delírio, que não são de todo, expressões equivalentes. Delírio (em inglês, delusion) é uma convicção persistente e inabalável, ${ }^{7}$ ou seja uma alteração do conteúdo do pensamento, que pode acontecer em inúmeras psicoses (e.g. orgânica, esquizofrénica, maníaco-depressiva, etc...) mas cuja ocorrência não obriga nem depende da existência de uma alteração do estado da consciência como é o caso do delirium. ${ }^{8}$

4) Finalmente, uma chamada de atenção para o uso de benzodiazepinas (e.g. diazepam, lorazepam, midazolam, etc...) no tratamento do delirium: são fármacos que podem, por si só, causar ou agravar a vasta maioria dos casos de delirium, pelo que devem ser evitados de todo, ou usados só e apenas, quando a etiologia já está bem definida: nomeadamente em casos de abstinência de substâncias depressoras do sistema nervoso central (e.g. álcool, benzodiazepinas, barbitúricos, etc...) ou intoxicação com psicoestimulantes (e.g. cocaína, anfetaminas, metanfetaminas, etc...). ${ }^{9}$

1980;100:682-91.

3. Bierman AS. Functional status: the sixth vital sign. J Gen Intern Med. 2001;16:785-6. 
4. Morone NE, Weiner DK. Pain as the 5th vital sign: exposing the vital need for pain education. Clin Ther. 2013;35:1728-32.

5. Waller A, Groff SL, Hagen N, Bultz BD, Carlson LE. Characterizing distress, the 6th vital sign, in an oncology pain clinic. Curr Oncol. 2012;19:e53-9

6. Meagher D. Delirium: the role of psychiatry. Adv Psychiatr Treat. 2001;7:433-42.

7. Duarte C, Choi KM, Li CL. Delírio de infestação parasitária associado a diálise tratado com aripiprazol, Acta Med Port. 2011:24:457-62.

8. Cerqueira GL. Delirium e delírio. Portal dos Psicólogos. 2015. [consultado 2018 jan 31]. Disponível em: http://www.psicologia.pt/ artigos/textos/A0931.pdf.

9. Alagiakrishnan K. Delirium. Medscape. Aug 23, 2017. [consultado 2018 jan 31]. Disponível em: https://emedicine.medscape.com/ article/288890-medication\#3.

\section{João GAMA MARQUES $\square^{1,2}$}

1. Hospital Júlio de Matos. Centro Hospitalar Psiquiátrico de Lisboa. Lisboa. Portugal.

2. Clínica Universitária de Psiquiatria e Psicologia Médica. Faculdade de Medicina. Universidade de Lisboa. Lisboa. Portugal.

Autor correspondente: João Gama Marques. joaogamamarques@gmail.com

Recebido: 01 de fevereiro de 2018 - Aceite: 02 de fevereiro de 2018 | Copyright @ Ordem dos Médicos 2018

https://doi.org/10.20344/amp.10326 